\title{
THE THEORY OF KNOWLEDGE IN CONTEMPORARY EPISTEMOLOGY
}

\author{
M. Shamshiri \\ Assistant professor, Khorasgan Branch, Islamic Azad University, Isfahan, Iran
}

Published online: 15 May 2016

\begin{abstract}
Contemporary philosophy in the west has begun with emphasizing "subjectivism" and the theory of "knowledge". Discussing the nature of knowledge leads inevitably to investigating the nature of "belief". However, it is important to note that knowledge is always something more than mere belief. To demarcate between truthful and untruthful belief we must have certain criteria. In this essay, an analytical approach has been adopted to first present a historical review of the meanings of "knowledge" and then to discuss the three parameters of knowledge (belief, truth, justification) in contemporary epistemology. The main ideas with regard to truthful belief and epistemological justification are investigated within the framework of two approaches: foundationalism and coherentism.
\end{abstract}

Keywords: knowledge; epistemology; belief; truth; justification.

Author Correspondence, e-mail: mo_shamshiri@yahoo.com

doi: http://dx.doi.org/10.4314/jfas.v8i3s.164

\section{INTRODUCTION}

The nature and domain of knowledge have always been one of the most basic issues in philosophy especially with the shift from the "object" to the "subject". Generally, western philosophers argue that knowledge is gained through experience and observation and is expanded through deduction. Discussing the issue of knowledge leads inevitably to the problem of beliefs because the same argument can be applied to the issue of justifiable beliefs. It is obvious that we 
all have many beliefs. However, how can one be sure which of these beliefs are truthful? What one wants is not mere belief but rather knowledge and understanding. This means that belief and knowledge are not the same. Knowledge is always something more than belief. To only have a belief is not enough for something to be called knowledge. Furthermore, an untruthful or wrong belief or a belief based on conjecture, even if it appears be truthful in one way, cannot be considered knowledge.

\section{EPISTEMOLOGY}

Epistemology is made of two Greek words: episteme which means knowledge and logos which means studying or theory. Epistemology has conventionally been equated with theory of knowledge. The theory of justification addresses the problem of justification in contemporary epistemology as a key issue (Audi, 1998).

Western epistemologists have proposed many different definitions for epistemology, some of which are included in the following:

- Epistemology is the study of knowledge and justification (Dancy, 1991).

- The theory of knowledge is the science of belief justification, that is, the justification for having a belief (Chisholm, 1989).

- Epistemology is enquiry into the nature and grounds of knowledge. 'What can we know, and how do we know it?' are questions central to philosophy, and knowledge forms the main topic of epistemology, along with its relation to other cognitive notions like belief, understanding, reason, judgement, sensation, reception, intuition, guessing, learning, forgetting (Lacey, 1991).

- Epistemology is concerned with the nature, sources and limits of knowledge (Edwards, 1967).

- Epistemology deals with the nature of knowledge and belief justification (Pojman, 1993).

The above definitions show that the focal point of all epistemological discussions is in one way or "knowledge" and the general theory of knowledge (rather than specific forms of it). Similar to other branches of knowledge, epistemology raises certain questions with regard to its object of study including: Is knowledge possible? What is knowledge made of? How is knowledge different from justified belief? What is the criterion for belief justification? What is the significance of justification and truth in knowledge? 
Different schools of philosophy have tried to answer the above and other similar questions in their own special ways. With the growing importance of the issue of knowledge one comes to recognize that these questions have occupied the central stage in the history of western philosophers and epistemologists. It is worth mentioning that when we talk about knowledge in epistemology we refer to a special form of knowledge as exemplified in the phrase: "knowing that". In such cases the object of knowledge is a proposition/statement, therefore, it is called "propositional knowledge". In this configuration, "that" comes between knowing (sometimes implicit) and the claimed proposition (object of knowledge). For example, "I know [that] it is sunny." This form of knowledge describes something and is therefore referred to as "descriptive knowledge".

\section{Analyzing the parameters of knowledge}

Despite many objections and rejections there is a general consensus with regard to a tripartite definition of knowledge which includes the three parameters of belief, truth and justification.

\section{Belief}

Belief is the first of the three elements constituting knowledge. Two views, namely, externalism and internalism, have been proposed with regard to the issue of belief. This view, beginning from Plato and continuing today, assigns the position of beliefs to propositions. In other words, the true object of belief is a proposition. According to this view, belief is a mental and internal receptive state in relation to the content of a proposition. The external relation of the proposition is in terms of truth and the internal relation is in terms of the connection with the internal state of the subject. Knowledge is not gained unless such a relation between the proposition and the subject is created. Belief is the result of this relation. This is why belief is considered to be accepting a proposition.

\section{Truth}

The other condition for knowledge is truth. According to this condition, we cannot claim to have knowledge about something which is untruthful. Historically, the issue of truth can be traced back to Plato and Aristotle. This has been taken up in contemporary philosophy by the followers of rationalism, experientialism and positivism with regard to the meaningfulness of a proposition. It must be noted that the issue of truth was limited to finding examples in the past while it gradually turned to discussing the nature of truthfulness itself. 
Although all of us have a general understanding of truthfulness (truth) and other words associated with this concept, questioning the nature of truth is a basic and difficult problem for the philosophers. There is no clear consensus among the philosophers about the problem of truth. Nevertheless, there is a common view which asserts that one needs to distinguish between truth at the level of definition from truth at the level of examples. As in discussing knowledge and belief where propositional knowledge/belief is focused on, truth in epistemology refers to propositional truthfulness rather than common meanings of truth.

The main theories of truth in epistemology are as follows:

- The correspondence theory of truth: This is the most traditional and the most familiar theory of truth. According to this theory, a proposition is truthful only when it corresponds to reality. This theory signifies that truth is the objectivity of beliefs. The most important assumption upon which this theory is built is realism. Realism asserts an existence and realization of reality independent of our minds and beliefs. Realism also asserts that the human mind can discover and perceive the external reality.

- The theory of coherentism: According to this theory, a proposition is truthful when it constitutes a coherent system with other propositions. No belief is independent and since it is an element in a larger whole its truthfulness can be determined in relation to this whole.

- The theory of testimony: According to this theory, a proposition is true only when it is verifiable/can put to testimony. Testimony refers to something that has the value to be expressed. Proponents of this theory argue that prior to expressing or proving something we look for testimony and witness for our expressions. Most often, to find a witness is enough for our expressions. The distinction between this theory from the theory of correspondence lies in the former's attention to and emphasis on finding a witness and proof.

- The theory of pragmatism: The roots of this theory goes back to the school of pragmatism in philosophy. Accordingly, a proposition is truthful when a belief of it leads to "pragmatic/functional/doxastic" results. The words, "pragmatic" means "functionality" and "usefulness". Proponents of this theory argue that a belief should be considered like a map which guides us. A good and efficient map is one which helps us in an appropriate 
and reasonable way to find the path in our investigation. In this view, the pragmatic function of beliefs is foregrounded.

- Alternative theories: The objections and critiques leveled against the above theories made a group of people to come to the conclusion that there is in fact no theory about truth and truthfulness. This theory asserts the impossibility of theory about truth. The origins of this theory go back to Frege, Magee, Quine, and others. The main claim in this theory is as follows: The fact that A is true only means that. Therefore, phrases like "true that" are not needed and can be deleted because they do not signify anything nor do they give us any new information and are only added to the proposition out of fun and play. As an example, note that there is no semantic difference or preference of one over the other between "It is true that it is raining" and "It is raining."

In line with this latter theory, another theory known as "semantic ascent" has been offered (Quine, 1960). Truth, in this view, is the instrument for semantic ascension. Meaning in this theory refers to the relation between words and world, in other words, between the speech and what it refers to. There is a semantic relation between the proposition "It is raining" and the weather conditions which determines the truthfulness/untruthfulness of this proposition. The concept of truth only allows us to talk about our understanding of the world - in this case, the weather condition.

\section{Justification}

The third condition for knowledge is justification. According to this necessary condition we cannot claim to have knowledge about our beliefs without justification. Most contemporary epistemologists believe that knowledge requires justification (Audi, 1993), which emphasizes the necessity of presenting reasons and justifications for a belief or knowledge. The basis of justification is presenting reasons. Presentation is a form of argumentation rather than acceptance. The difference illuminates also the distinction between justification and truth. Truth corresponds to acceptance while justification correspondence to argumentation and testimony. Truth is the relation of the proposition to the external world while justification is the relation of the propositions with one another. Truth refers to the objective world whereas justification refers to the world of the mind. It is worth mentioning that in the focus of traditional philosophy was on truth while the focus of contemporary philosophy is on justification. 
The two main philosophical schools which directly address the issue of knowledge justification are the following:

- Foundationalism

- Coherentism

\section{Foundationalism}

Epistemological foundationalism has been understood in many different ways. We content with discussing two of these views. One of the most influential views in epistemology is the classical foundationalism (Dancy, 1991). Foundationalism asserts that justification is structured like a building. Some beliefs are inherently justified while other beliefs are justifiable only if they are built upon and supported by these basic beliefs. In other words, knowledge justification has a structure and thus beliefs are divided into two kinds: basic beliefs (essentially justified) and superstructure beliefs. The latter kind of beliefs is justifiable only by relying upon the first group of beliefs. Although the distinction between basic and superstructure beliefs is a structural distinction, classical foundationalists asserted a distinction in terms of content too. Accordingly, the content of basic and nonbasic beliefs is different because these beliefs are in connection with the core of sensory states, i.e. immediate experience. Thus, basic beliefs are those which refer to our sensory states and immediate experiences. In foundationalism, sensory perceptions and immediate experiences are beliefs which are essentially independent and at the same time fulfill the need of other beliefs for justification. It can be concluded that classical foundationalism is a kind of experientialism since it assumes that all our knowledge is derived from experience. A belief which is outside the limits of experience, if required to be justified, should be justified by relying on the beliefs which are within the domain of sensory states. This assumption is based on another aspect of classical foundationalism which asserts that beliefs within the limits of sensory and motor states are infallible and reliable and thus can play the role of basic beliefs.

The latest understanding of foundationalism is offered by contemporary epistemologists, sometimes referred to as modified foundationalism (Audi, 1993). Generally speaking, contemporary foundation lists have turned to a kind of relativism and have come to the conclusion that foundational propositions may be different in relation to different people. This view is considered modified because of two reasons: first, in comparison to classical foundationalism, it has more moderate views about the credibility of basic beliefs; second, it uses 
a weaker criterion of cognitive dependence, i.e. there is a relationship between two codependent beliefs.

The above explanation shows that foundation lists differ with regard to what they consider as the sufficient conditions for a belief to become basic or no basic. Accordingly, they can be divided into extremist foundationalism (including classical foundationalism) and moderate foundationalism. The first group argue that a belief is essentially justifiable when it is infallible, certain and unmodifiable. However, the second group does not consider these three conditions as necessary for justification. Rather, they assume that it is enough for a basic belief to be probable and possible. Nevertheless, both groups argue content that the dependence of beliefs on one another is unidirectional, i.e. from basic beliefs to super structural beliefs.

\section{Coherentism}

Historically, coherentism has often been considered the opposite of foundationalism. It seems that our beliefs are not separate and independent parts. Rather, beliefs are codependent and together make what call knowledge. In the theory of coherentism, the criterion for justification is beliefs. Accordingly, a belief is justifiable to the extent that it is not incongruous with other beliefs. To put it differently, a belief is justifiable when the complex of beliefs to which it belongs or is a member of is a unified and coherent whole. The value of each belief depends on the role it plays in the whole complex of beliefs. If the coherence of a belief complex increases by eliminating or replacing a belief this means that the belief is not justifiable at the first place. Thus, a belief is justifiable when it is in a coherent relationship with the belief complex. The common theory of justification in this regard asserts that justification is the same with being rational. When something is coherent with the belief system of a person it means that it is rational to accept this belief based on previous beliefs. Frequently, people achieve coherence through reducing or eliminating the opposing or incongruous elements while if something is coherent with the belief system it is the most rational thing to accept it - in contrast to the incoherent elements. Therefore, it can be concluded that a belief complex with rational coherence justifies all its elements and members (Dancy, 1991).

In contrast to foundationalism, coherentism does not assume that a belief can be essentially justifiable. In this view, a belief is not justifiable unless it belongs to a belief system in which beliefs mutually support one another. Furthermore, the primary object of justification is not individual or personal beliefs; rather, it is a belief "system". A belief complex is justifiable only if 
the constituent beliefs are effectively coherent. Individual beliefs become justifiable because of their membership in such belief complexes. Thus, for a follower of coherentism, epistemological justification is rather a holistic concept rather than structured into base and superstructure. It is wrong in this view to assume that basic beliefs are fundamentally justified so that their justification can be extended to other beliefs. Rather, justification is gained through the congruency and codependency of beliefs in a system, i.e. coherence.

What is agreed upon in the foundationalist school today is in fact the same with modified/moderate foundationalism. This has led to the assumption that epistemology has moved from justification to reviving coherentism. One of the most prominent twentieth century foundationalists, namely, Wilfrid Sellars (1912-1989) has famously said that no belief is essentially justified (Sellars, 1963), and beliefs are justifiable only by referring to other beliefs. Thus, in epistemic justification, there is one step from asserting that no belief is essentially justified to the theory of coherentism. This step has been taken by showing that some beliefs become justified by referring to other justified beliefs. This raises the question: "What makes the following beliefs justified?" If one answers that other justified beliefs, the question still holds. Extending the question one can reach the conclusion that there are three different methods with regard to the structure of epistemic justification. First, there should be an infinite regression of justifiers. For example belief A is justified by reference to belief B, and belief B is justified by reference to belief C, ad infinitum. However, most philosophers believe that if there is no limit to this regression then none of the primary members of the regression would be justified and thus it will cause skepticism, i.e. nothing will be epistemically justified. Second, as emphasized by foundationalists, belief A is justified by reference to belief B and belief B is justified by reference to belief $\mathrm{C}$ until we reach a belief which is essentially justified, and thus, ending the regression. The third method accepts a kind of circular acceptance in itself. Belief A is justified by reference to belief $B$ and belief $B$ is justified by reference to belief $C$ until we reach a belief is justified by reference to belief A, and similarly, other primary beliefs in the complex. We face a set of beliefs which mutually support each other, i.e. belief $\mathrm{A}$ is justified by reference to beliefs which are themselves supported by reference to belief A.

\section{CONCLUSION}

As discussed in details, it is clear that to talk about "knowledge "without taking into account the issue of "beliefs" is almost impossible. An untruthful or wrong belief or a belief based on 
conjecture and guess, even if it appears truthful, cannot be considered knowledge. Now, is it possible to add something to the concept of truthful belief so that it becomes knowledge? Historically speaking, Plato was the first person to answer this question. In Meno and especially in Theaetetus, Plato proposed an explanation of knowledge which as "justified true belief" (1988). In any case, for Plato, doxa (as mere belief and inferior to real knowledge) is lower than episteme. Similarly, contemporary western epistemologists unanimously define knowledge as "justified true belief". According to this view, there are three necessary conditions for something to be called knowledge: belief, truth and justification. Anyone who lacks one of or more of these conditions cannot claim that "I know that..." These conditions can help someone gain knowledge; they are necessary and sufficient conditions.

Among the above parameters (belief, truth, justification), "justification" has become the focal point in contemporary epistemology. This can be explained within the two paradigm of foundationalism and coherentism, each having its own arguments, as illustrated in this essay.

\section{REFERENCES}

[1] Audi, R. Epistemology, Routledge, 1998.

[2] Audi, R. The structure of justification, Cambridge university press, 1993.

[3] Chisholm, R.M. Theory of knowledge. Prentice Hall, 1989.

[4] Dancy. J. An introduction to contemporary epistemology, Basil Blackwell, 1991.

[5] Edwards, P. The encyclopedia of philosophy, London: Collier MacMillan press, 1967.

[6] Lacey, A.R. Dictionary of philosophy, Routledge, 1991.

[7] Plato. Complete works. Vol III. [Persian].Trans. Mohammad Hasan Lotfi. Tehran: Khrazmi, 1988.

[8] Pojman, P. The theory of knowledge: classical and contemporary readings, California: Wadsworth press, 1993.

[9] Quine, W.V.O. Word and object, Cambridge, Ma: Mitpress, 1960.

[10] Sellars, W. Science, perception and reality, London: Routledge and kegan paul, 1963.

\section{How to cite this article:}

Shamshiri M. The theory of knowledge in contemporary epistemology. J. Fundam. Appl. Sci., 2016, 8(3S), 30-38. 